\title{
Evaluation of Serum Level of Neurokinin A in Vitiligo Patients
}

\author{
A.A.Ibrahim, E.M.Akl, S.A.El-Fallah and D.K.E.A.El-Nadi \\ Venereology \& Andrology Dept., Faculty of Medicine, Benha Univ., Benha, Egypt \\ E-Mail:Doaa25@gmail.com
}

\begin{abstract}
Vitiligo is a secured pigmentary disarray of the skin and mucous layers that is portrayed clinically by the improvement of particularly included white macules and patches of skin and hair ,Neurokinin An is accessible in excitatory neurons and secretory cells of the hypothalamic-pituitary-adrenal center .Additionally, both SubstanceP are neurokinin An is found in the neurosensory structure and change a wide extent of red hot and tissue fixing measures. The purpose of the work is to evaluate Neurokinin A serum level in vitiligo patients and its relationship with individual fulfillment. fifty subjects encountering non segmental vitiligo and avowed by wood's light and thirty clearly solid subjects, sex and age composed individuals who filled in as a control in the Banha school clinical center, they were attempted serologically for level of neurokinin A level with examination of individual fulfillment by dermatology life quality record questionair. The mean age with patients was $30 \pm 10.8$ years old, while in control it was $27 \pm 7$ years old. There was no immense differentiation between the two social occasions as regard age $(\mathrm{P}=0.06$.(The understanding get-together included $18(36 \%)$ male and $32(64 \%)$ female, while controls included 14(46.7\%)male and $16(53.3 \%)$ females. There was no enormous differentiation between the two social occasions as regard sex $(\mathrm{p}$ regard $=0.35$ ). The results of our assessment revealed that patients had high quantifiably basic higher NKA $(\mathrm{p}<0.001)$ with mean \pm SD $(500.91 \pm 119.3)$ than control bundle with mean \pm SD (109.55 \pm 80.51$)$.vitiligo has genuine impact on close to home fulfillment especially on more young age pack with mean age of the generally affected patients 23.8 years old . NKA is high in vitilligo patients differentiated and controls. There was positive relationship among's reality and dermatology life quality rundown with verifiably enormous worth.
\end{abstract}

Keywords: Vitiligo, Neurokinin A, Dermatology life Quality Index.

\section{Introduction}

Vitiligo is a gained pigmentary turmoil of the skin what's more, mucous movies that is portrayed clinically by the progression of especially enclosed white macules and patches of skin and hair with nonattendance of melanocytes minutely. Around the globe, the power of vitiligo goes from 0.4 to $2.0 \%$, with locale of more important or lesser ordinariness. It may appear at whatever stage throughout everyday life and impact the two sexes [1].

Vitiligo is requested into non-segmental and segmental subtypes; the last occur in a minority (5-16\%) of patients. Starting and course of the sickness may move by subtype. Likewise, individuals with vitiligo may experience immense mental signs [2].

The particular pathogenesis of vitiligo is still to be explained. Various frameworks, including metabolic anomalies, oxidative weight, time of combustible center individuals, cell detachment and safe framework responses, may add to the pathogenesis. Other pathogenic causes may join inherited effects, tactile framework off-kilter nature [3].

In vitiligo, obvious features are apoptosis of melanocytes achieved by cytotoxic immune reaction, and breakdown of utilitarian melanocyte-keratinocyte crosstalk required for common pigmentation [4].

Neuropeptide-Y (NPY) is a 36-amino destructive peptide which can induce melanocyte dendricity and looks into the rule of cell substrate security, cell motility and shape [5].
Neurokinin A, when known as substance $\mathrm{K}$, is a neurologically activepeptidewhichtranslated from the pre-protachykinin quality . Neurokinin A was isolated from porcine spinal string in 1983 by von Euler and Gaddum [6].

Neurokinin An is accessible in excitatory neurons and secretory cells of the hypothalamic-pituitaryadrenal turn .Additionally, both SubstanceP are neurokinin An is found in the neurosensory structure and manage a wide extent of red hot and tissue fixing measures [7].

Neurokinin A connections to the G-protein coupled receptor at last extending the appearance of inositolphosphate and calcium second messengers,Each receptor shows a specific affection for either neurokinin An or substance P peptides. The two peptides, regardless, can go probably as full agonists on either receptor, disregarding the way that their power is lessened when not bound to their specific receptor [8].

\section{2 .Patients and methods}

Between April 2018 and October 2019, fifty subjects experiencing non segmental vitiligo and affirmed by wood's light and thirty clearly solid subjects, sex and age coordinated people who filled in as a benchmark group.

The patients were chosen from patients going to the Outpatient Clinic of Dermatology and Andrology Department of Benha University Hospital. Every one of these competitors were surveyed for level of neurokinin 
An in their serum and appraisal of effect of their personal satisfaction by dermatology life quality file questionair

The patients were Active vitiligo injuries inside the most recent a half year as per (VIDA) score. The investigation avoided Patients with other skin sickness than vitiligo ,Patient with segmental vitiligo ,Patients with other immune system infections, Patients with diabetes, hypertension, kidney or liver illnesses ,Pregnant and lactating subjects

\section{(A) Full history taking including}

Personal history: name, age, sex, residence, occupation, special habits like smoking ,History of present illness, Treatment history ,Family history of vitiligo.

(B) General medical examination

To detect the signs of other systemic diseases and the presence of any exclusion criteria.

\section{(C) Local Dermatological examination}

Patients were carefully examined for site, size, distribution and clinical type of vitiligo, extent and severity of vitligo was evaluated according to Vitiligo disease activity score (VIDA) and (VASI) score .

\section{(D) Serological evaluation}

\section{- Sampling}

$3 \mathrm{ml}$ of venous blood samples were withdrawn under aseptic conditions, coagulated and then centrifuged for 10 minutes at $1300 \mathrm{rpm}$. The serum was separated from blood and subdivided in two aliquots and freezed at $40 \mathrm{c}^{\circ}$ till analyzed.

\section{- Measurement of Neurokinin A.}

\section{Principle of the test}

The kit used a double-antibody sandwich enzymelinked immunsorbentassay(ELISA) to assay the level of human Neurokinin A (NKA) in sample. The kit was supplied from NOVA, no.18.keyuan Road.Beijing,china

\subsection{Statistical analysis}

Data management and statistical analysis were performed using the Statistical Package for Social Sciences (SPSS)

Numerical data were summarized using means, standard deviations and ranges, categorical data were summarized as numbers and percentages. Comparisons between multiple groupswere done using repeated measure ANOVA test, post hoc comparisons were done and adjustment for multiple comparisons were done using Bonferroni correction.

All p-values are two-sided. P-values $<0.05$ were considered significant while $>0.05$ statistically insignificant $\mathrm{P}$ value $<0.01$ was considered highly significant $(* *)$ in all analyses.

\section{Results}

Socio demographic and clinical characteristics of patients and controls ( Comparison between case and control groups according to personal factors)

Table (1) Comparison between patients and controls as regard personal factors.

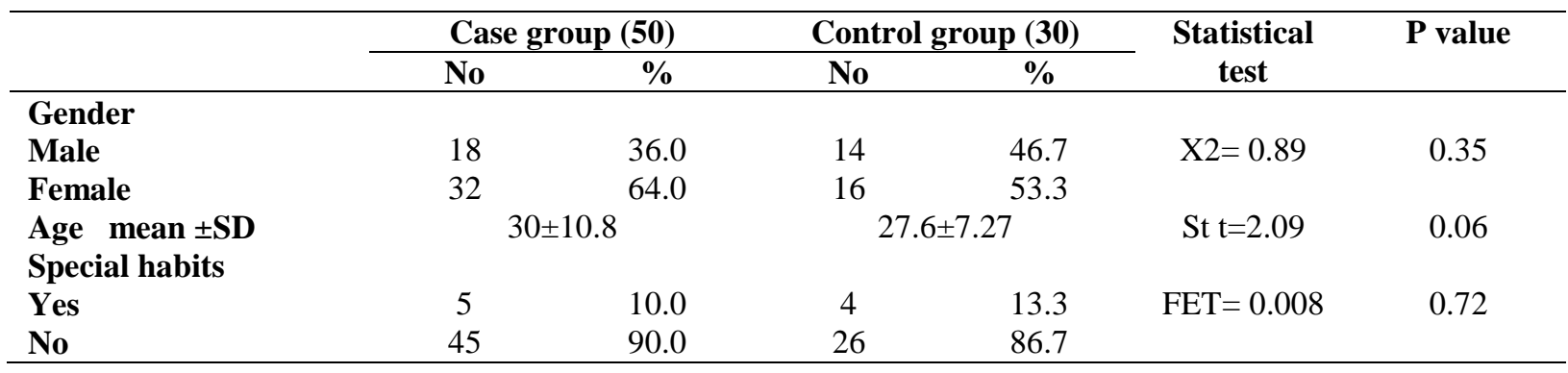

$\mathrm{T}=$ independent $\mathrm{t}$ test, $\mathrm{p}<0.05=$ statistically significant.

The mean age of patients was $30 \pm 10.8$ years while the mean age of controls was $27 \pm 7$ years with $(\mathrm{P}=0.06)$.

The patient group included $18(36 \%)$ males and $32(64 \%)$ females, while controls included $14(46.7 \%)$ males and $16(53.3 \%)$ females.

There was no significant difference regarding gender $(\mathrm{P}=0.35)$.

There was no significant difference regarding age, gender and special habit.
Neurokinin expression according to different variables(gender,special habit, family history ,medical history ,history of systemic diseases ,course VIDA score ,DLQI and sun exposure).

As regard to values of neurokinin there is no significance in different variables except for patient who have no medical treatment with mean value is 497.71 and the $\mathrm{p}$ value is .037 which is significant 
Table (2) Correlation between neurokinin and other variables.

\begin{tabular}{|c|c|c|c|c|c|}
\hline \multirow{2}{*}{ Case group $(50)$} & \multirow{2}{*}{$\mathbf{N}$} & \multicolumn{2}{|c|}{ Neurokinin } & \multirow{2}{*}{$\begin{array}{c}\text { Statistical } \\
\text { test }\end{array}$} & \multirow{2}{*}{$P$ value } \\
\hline & & Mean & $\pm \mathrm{SD}$ & & \\
\hline \multicolumn{6}{|l|}{ Gender } \\
\hline Male & 18 & 520.73 & 102.17 & St $\mathrm{t}=0.88$ & 0.38 \\
\hline Female & 32 & 489.76 & 128.13 & & \\
\hline \multicolumn{6}{|l|}{ Special habits } \\
\hline Yes & 5 & 504.41 & 98.08 & St $\mathrm{t}=0.07$ & 0.95 \\
\hline No & 45 & 500.52 & 122.37 & & \\
\hline \multicolumn{6}{|l|}{ Course } \\
\hline Regressive & 2 & 449.01 & 49.51 & St $\mathrm{t}=0.62$ & 0.54 \\
\hline Progressive & 48 & 503.07 & 121.11 & & \\
\hline \multicolumn{6}{|l|}{ Medical history } \\
\hline No & 37 & 497.71 & 116.24 & $\mathrm{~F}=3.55$ & $0.037 *$ \\
\hline Tropical & 5 & 404.79 & 35.98 & & \\
\hline NB-UVB & 8 & 575.8 & 127.84 & & \\
\hline \multicolumn{6}{|l|}{ FH } \\
\hline$+v e$ & 2 & 609.7 & 184.84 & St $t=1.33$ & 0.19 \\
\hline -ve & 48 & 496.38 & 116.57 & & \\
\hline \multicolumn{6}{|c|}{ History of systemic disease } \\
\hline Yes & 4 & 587.29 & 159.23 & 1.53 & 0.13 \\
\hline No & 46 & 493.4 & 114.4 & & \\
\hline \multicolumn{6}{|l|}{ VIDA score } \\
\hline+1 & 4 & 486.35 & 220.3 & $\mathrm{~F}=0.09$ & 0.96 \\
\hline+2 & 13 & 497.25 & 108.95 & & \\
\hline+3 & 15 & 494.02 & 113.44 & & \\
\hline+4 & 18 & 512.53 & 115.07 & & \\
\hline \multicolumn{6}{|l|}{ DLQI } \\
\hline Small & 1 & 360.74 & - & $\mathrm{F}=0.71$ & 0.50 \\
\hline Moderate & 34 & 505.62 & 119.69 & & \\
\hline Very large & 15 & 499.58 & 120.8 & & \\
\hline
\end{tabular}

\section{Discussion}

Vitiligo is a multifactorial, idiopathic, depigmentary disarray of the skin that is portrayed by ruinous loss of melanocytes. Continuous epidemiological assessments point by point that the inescapability of vitiligo went from $0.1 \%-0.2 \%$ of the overall people, with higher ordinariness in Africa and female predominance [11].

The pathophysiology of vitiligo is still commonly dark. Regardless, a couple of reports displayed that autoimmunity addresses the basic pathophysiological pattern of vitiligo which makes considering different environmental and provocative triggers in genetically defenseless individuals [10].

Neurokinin An is known to expect a huge capacity in neurotransmission in the nociceptive pathway at the level of the essential synapse. Neurons that contain tachykinin peptide found in material ganglia have little cell bodies and unmyelinated $\mathrm{C}$-strands or gently myelinatedA $\delta$ fibers with moderate conduction speeds. These neurons are responsible for nociceptive responses to physical (warm, mechanical) and manufactured enhancements. Moreover they are obligated for period of neurogenic disturbance by conveying neuropeptides from their periphery endings [12].

In this examination, female cases were $64 \%$ this agree with [13] in which the female people spoke to $65.9 \%$ of the model. In any case, various makers have set up that there are no differentiations between sex [14].

In this assessment, the mean age was 30 years in patients gathering. Unmistakable mean of ages were found in another assessment 31.3 years , 28.67 years, 36.35 years, 37.14 years and 28.11 years respectively [14]. This agree with the typical time of presentation itemized recorded as a hard copy as half of the patients with vitiligo present before the age of 20 years and very nearly $70-80 \%$ before the age of 30 years (15) However, an assessment in India declared adelay start of the ailment, with a mean age of 55 years [13]. These data fortified that vitiligo is a disease that occurs at whatever stage throughout everyday life.

This examination saw presence of family parentage in $4 \%$ of patients. This is in against [10] who point by point that family parentage went from $34 \%$ to $38.7 \%$. Various assessments conjectured that $10.6 \%$ and $9 \%$ in their general population [16]. 
Y.Zhang et al. [9] speculated that there was a higher repeat of family lineage, since it was driven in a general population in which a couple of family members were affected by vitiligo, and there was moreover a more cautious assessment of these families.

In this assessment, concerning the site of starting, the sun revealed districts was the regularly impacted. This is according to [17] who declared that facial vitiligo has been represented some place in the scope of $17 \%$ and $35 \%$ of the subjects in India. This can be explained by that the basic site of affiliation is sun-revealed districts. In other examination the upper member has been represented more than in 33\% of the cases [16]. In any case, an examination in India nitty gritty that $44 \%$ of the patients demonstrated lower member as a site of start of vitiligo [20].

In this examination, NK-A was basically higher in cases appeared differently in relation to controls. ROC assessment was refined for NK-An in examination of vitilligo, It revealed affectability 100 ,specifity 100 at cut of point 333.35

There is past examination of NKA anyway in alopecia circle air through. In [5]. found that there was a basic augmentation of the mean serum level of neurokinin An in alopecia flow air through patients stood out from controls. Similarly there was positive enormous association among's earnestness and serum neurokinin A level, furthermore In this assessment, there was a basic augmentation of the mean serum level of NKA in psoriatic patients differentiated and controls. There was positive association among's earnestness and serum neurokinin A with quantifiably basic worth. There was positive connection between's PASI score and LDL , cholesterol and FBS..

In this examination DLQI has more impact on females than folks with $(\mathrm{P}=0.199)$ and this agree with [9]. on his examination of 119 patients with vitiligo and various makers found women to be more mortified and self-conscious about the contamination, more incapacitated in their step by step life timetable, and more affected in their choice of clothing,also [19]. study2013 they found that female sex was connected with higher DLQI scores in assessments $(\mathrm{P}=0.003)$, and male sex was connected with higher DLQI scores seeing somebody $(P=0.040)$, regardless of the way that women search for treatment for the issue even more a large part of the time.

In this assessment the patient with sun revealed locales with vitilligo had greater impact on their life than non uncovered zones and this agrees with [17]. suggested that the 'recognizable wounds' social event scored higher differentiated and the 'imperceptible injuries' concerning DLQI score and exhibited that patients with evident bruises experienced a more raised degree of mocking.
In this examination As regard to DLQI the more energetic age had outrageous impact on life than more settled age with mean age 23.8 year and this agree with an assessment by [18] the most raised mean DLQI score was found in the third decade of life, anyway no authentic qualification was found between the age social affairs $(P=0.278)$ [19]. seen that the most raised mean DLQI regard was in the patient get-together developed 20-29 years, anyway by and large, no basic connections were found [20], and others didn't find any enormous association between's the DLQI score and age

To the extent we might realize this is the chief investigation which showed a colossal connection between Neurokinin An and vitiligo lack of protection.

\section{Conclusion}

In this study, NKA is high in vitilligo patients compared with controls. There was positive correlation between severity and dermatology life quality index with statistically significant value.

\section{Recommendations}

- Neurokinin a is needed to be measured in tissue and correlation with its serum level.

- Further studies are needed to evaluate NKA before and after treatment of vitiligo to show if there is any significant differences .

\section{References}

[1] A.Taieb, M. andPicardo, The definition and assessment of vitiligo; a consensus report of the Vitiligo European Task Force. -J Pigment Cell ResCompilation 20:27-35.J InvestigAllergolClinImmunol, Vol.19, PP.21-6, 2007.

[2] K. Ezzedine, V. Eleftheriadou, M. Whitton, N.van Geel , VitiligoLancet ,Vol.4;386(9988), PP.74-84, 2015.

[3] J.I.Silverberg and N.B.Silverberg Association between vitiligo extent and distribution and qualityof-life impairmentJAMA Dermatol. Vol.149(2), PP.159-64, 2013.

[4] V.M.Sheth, Y.Guo, and A.A.Qureshi,Comorbidities associated with vitiligo: a ten-year retrospective study. J Dermatol,Vol.227, PP.311-315, 2013.

[5] T.Prod'homme, M.S.Weber, L.Steinman, S.S.Zamvil,A neuropeptide-mediated inflammation, Y?Trends Immunol,Vol.27, PP.164-16, 2006.

[6] Nakanishi, Shigetada,"Molecular Mechanisms of Intercellular Communication In The Hormonal And Neural Systems". IUBMB Life,Vol.58 (5/6), PP. 349-357, 2006.

[7] I.R.Chandrashekar, S.M.Cowsik "Three-dimensional structure of the mammalian tachykinin peptide neurokinin A bound to lipid micelles" Biophys. J,Vol. 85 (6), PP.4002-11, 2003. 
[8] Maudsley, Stuart, The Mammalian Tachykinin Ligand-Receptor System: An Emerging Target For Central Neurological Disorders". CNS \& Neurological Disorders - Drug Targets, Vol. 9 (5), PP. 627-635, 2010.

[9] Y.Zhang, Y.Cai, M.Shi, S.Jiang, The prevalence of vitiligo: A meta-analysis. PLoS One,Vol.11, 2016.

[10] P.Manga, N.Elbuluk, S.J.Orlow.Recent advances in understanding vitiligo. F1000 Research,Vol.5, 2016.

[11] M.Rashighi, J.E.Harris,Vitiligo Pathogenesis and Emerging Treatments. Dermatol Clin,Vol.35, PP.257-65, 2017.

[12] M.S.Steinhoff , B.von Mentzer , P.Geppetti , C.Pothoulakis, Tachykinins and their receptors: contributions to physiological control and the mechanisms of disease, 2014.

[13] S.Dogra, D.Parsad, S.Handa, A.J.Kanwar,Late onset vitiligo: A study of 182 patients. Int J Dermatol,Vol.44, PP.193-6, 2005.

[14] S.B.Nejad, H.H.Qadim, L.Nazeman, R.Fadaii, Frequency of autoimmune diseases in those suffering from vitiligo in comparison with normal population. Pakistan J Biol Sci PJBS,Vol.16, PP.570-4, 2013.

[15] A.E.El-Taweel, E.Akl , M.N.William and A. El Fallah, Evaluation of Serum Neurokinin A Level in
Alopecia Areata Patients. Benha Medical J. Vol.36(2), PP.42-50, 2020.

[16] M.Karelson, H.Silm, K.Kingo, Quality of life and emotional state in vitiligo in an Estonian sample: comparison with psoriasis and healthy controls. ActaDermVenereol, Vol. 6, PP.446- 450, 2013.

[17] G.Schmid-Ott, T.Borchart, G.Nyderauer, V.Lamprecht, Stigmatization and life quality of patients with psoriasis and atopic dermatitis. Hautarzt,Vol.54, PP.852-857, 2003.

[18] V.Mashayekhi, Z.Javidi, B.Kiafar, Quality of life in patients with vitiligo: a descriptive study on 83 patients attending a PUVA therapy unit in Imam Reza Hospital, Mashad. Indian J DermatolVenereolLeprol,Vol.76, PP.592, 2010.

[19] M.A.Radtke, I.Schafer, A.Gajur, Willingness -to-pay and quality of life in patients with vitiligo. $\mathrm{Br}$ J Dermatol,Vol.161, PP. 134- 139, 2009.

[20] M.Dolatshahi, P.Ghazi, V.Feizy, Life quality assessment among patients with vitiligo: comparison of married and single patients in Iran. Indian $\mathbf{J}$ DermatolVenereolLeprol, Vol.74, PP.700, 2008. 